\title{
Modes of Cell Death Induced by Photodynamic Therapy Using Zinc Phthalocyanine in Lung Cancer Cells Grown as a Monolayer and Three-Dimensional Multicellular Spheroids
}

\author{
Sello L. Manoto, Nicolette Houreld, Natasha Hodgkinson and Heidi Abrahamse * \\ Laser Research Centre, Faculty of Health Sciences, University of Johannesburg, P.O. Box 17011, \\ Doornfontein 2028, South Africa; lmanoto@csir.co.za (S.L.M.); nhoureld@uj.ac.za (N.H.); tashar@uj.ac.za (N.H.) \\ * Correspondence: habrahamse@uj.ac.za; Tel.: +27-11-559-6406; Fax: +27-11-559-6884
}

Academic Editors: Augusto C. Tomé, João Paulo C. Tomé and Michael Hanack Received: 8 March 2017; Accepted: 9 May 2017; Published: 16 May 2017

\begin{abstract}
Photodynamic therapy (PDT) involves interaction of a photosensitizer, light, and molecular oxygen which produces singlet oxygen and subsequent tumour eradication. The development of second generation photosensitizers, such as phthalocyanines, has improved this technology. Customary monolayer cell culture techniques are, unfortunately, too simple to replicate treatment effects in vivo. Multicellular tumour spheroids may provide a better alternative since they mimic aspects of the human tumour environment. This study aimed to profile 84 genes involved in apoptosis following treatment with PDT on lung cancer cells (A549) grown in a monolayer versus three-dimensional multicellular tumour spheroids $(250$ and $500 \mu \mathrm{m})$. Gene expression profiling was performed $24 \mathrm{~h}$ post irradiation $\left(680 \mathrm{~nm} ; 5 \mathrm{~J} / \mathrm{cm}^{2}\right)$ with zinc sulfophthalocyanine ( $\mathrm{ZnPcS}$ mix $)$ to determine the genes involved in apoptotic cell death. In the monolayer cells, eight pro-apoptotic genes were upregulated, and two were downregulated. In the multicellular tumour spheroids $(250 \mu \mathrm{m})$ there was upregulation of only 1 gene while there was downregulation of 56 genes. Apoptosis in the monolayer cultured cells was induced via both the intrinsic and extrinsic apoptotic pathways. However, in the multicellular tumour spheroids $(250$ and $500 \mu \mathrm{m})$ the apoptotic pathway that was followed was not conclusive.
\end{abstract}

Keywords: photodynamic therapy; zinc phthalocyanine; monolayer; three-dimensional multicellular tumour spheroids

\section{Introduction}

Lung cancer is the most commonly diagnosed cancer, representing $12 \%$ of all diagnosed cancers and $18 \%$ of cancer related deaths in both males and females, worldwide [1,2]. The most common predisposing factor to lung cancer development is cigarette smoking. In addition, exposure to radon, second hand smoke, and other diseases such as HIV are also factors that could lead to its development [3,4]. Being an aggressive cancer, the treatment of lung cancer has remained a challenging task. Conventional treatments include; surgery, radiation therapy, and chemotherapy. The type of therapy chosen is dependent upon the cancer type (small cell or non-small cell), development stage, and genetic characterization. Patients often undergo more than one type of treatment [5]. The development of targeted therapies is significantly changing the management of lung cancers. Such treatments include those that target presumed important molecules in cancer cell proliferation and survival [6].

Photodynamic therapy 'PDT' has emerged as an effective phototherapeutic modality used in the treatment of non-neoplastic and neoplastic diseases. PDT involves the use of light at a specific wavelength to selectively activate a photosensitizer 'PS' in the presence of molecular 
oxygen [7]. The activation of the PS results in the generation of singlet oxygen, or other reactive oxygen species (ROS), which causes oxidative damage to cellular components by damaging different biomolecules-including proteins, DNA, and lipids—and so leads to tumour cell death [8,9]. Although many PSs are being developed and used in targeted therapy, a 'good' PS should ideally be a single pure compound, it should have a strong absorption peak in the red to near-infrared spectral region (between 650 and $800 \mathrm{~nm}$ ), it should possess a substantial triplet quantum yield, have no dark toxicity and a relatively rapid clearance rate from normal tissues [10].

Photofrin and hematoporphyrin are the most widely studied PSs in experimental and clinical trials [6]. Photofrin is clinically approved by the Food and Drug Administration 'FDA', of the United States of America, for the treatment of cancer. The main problems of this PS include long term photosensitivity, high degree of chemical heterogeneity, and poor absorption of tissue penetrating red light [11]. These downfalls have encouraged scientists to focus on research around the synthesis and testing of second generation PSs [11]. Among these are the phthalocyanines which have intense absorption in the visible red region, high efficacy in producing singlet oxygen, and ease of chemical modification and formation [12].

Traditionally, screening of drugs, for the treatment of cancer, has been conducted on conventional two dimensional '2D' monolayer cultures of cells [13]. However, monolayer cultures, while useful for studying treatment effects, are too simple to replicate the many heterogeneous treatment effects found in vivo. Monolayer culture tests may provide misleading data which may not be easily translated to in vivo studies. In drug discovery research, approximately $10 \%$ of compounds progress successfully through clinical development, and many fail during clinical trials largely due to the lack of clinical efficacy and/or unacceptable toxicity. Additionally, a portion of these failures is attributed to data collected from the 2D monolayer culture tests where cellular responses to drug therapy are altered due to their 'unnatural' microenvironment [14].

Therefore, to bridge the gap between conventional monolayer cell studies and animal experiments, there is a need for the development of new cell culture models [15]. Multicellular tumour spheroids 'MCTSs' are three-dimensional '3D' tumour cell aggregates and serve as an important model in cancer research for the evaluation of therapeutic interventions since they mimic different aspects of the human tumour environment $[15,16]$. These models provide valuable tools for in vitro identification of potential anticancer drug targets [16].

In non-cancerous cell cultures (normal cells), differences in phenotype and genotype when grown in 2D and 3D in vitro models have been documented. Researchers have identified that these differences are even more profound in cancer cells cultured in 3D when compared to a monolayer culture $[17,18]$. For experimental testing of the efficacy of new drugs in the treatment of cancer, it is essential to mimic in vivo environments as close as possible to yield accurate results, and the use of MCTSs can provide such environments.

The three key cell death pathways evoked by PDT are apoptosis, necrosis, and autophagy. Apoptosis is generally the main response to cells treated with PDT and in the ablation of tumours [11,19]. Stimuli responsible for triggering apoptosis include; tumour necrosis factor (TNF), DNA damage, ROS, and increased intracellular calcium levels. It is, however, unclear which of these pathways are triggered resulting in apoptotic cell death by PDT [20]. Studying the differential expression of genes involved in apoptosis could provide a clear understanding of PDT mediated cell death. In our previous study, it was demonstrated that photoactivated $\mathrm{ZnPcS}_{\text {mix }}$ induces apoptotic cell death, and that monolayer cells and MCTSs $(250$ and $500 \mu \mathrm{m})$ differ in their response to PDT, with MCTSs $(250 \mu \mathrm{m})$ being the model most susceptible to PDT. The aim of the present study is to determine the genes involved in apoptosis mediated cell death following PDT, using the same parameters as our previous studies [16,21]. 


\section{Results}

\subsection{Nuclear Morphology}

The Hoechst 33342 stain was used to evaluate apoptosis in the PDT treated cells (Figure 1). The monolayer cells treated with $\mathrm{ZnPcS}_{\text {mix }}(10 \mu \mathrm{M})$ or irradiated at $5 \mathrm{~J} / \mathrm{cm}^{2}$ alone showed no changes in nuclei morphology and appeared similar to that of the untreated monolayer cells 1 and $24 \mathrm{~h}$ post incubation. Photoactivated $\mathrm{ZnPcS}_{\text {mix }}$ at $10 \mu \mathrm{M}$ resulted in smaller numbers of nuclei, shrinkage of the nuclei, which is indicative of apoptosis, $1 \mathrm{~h}$ and 24 post PDT.

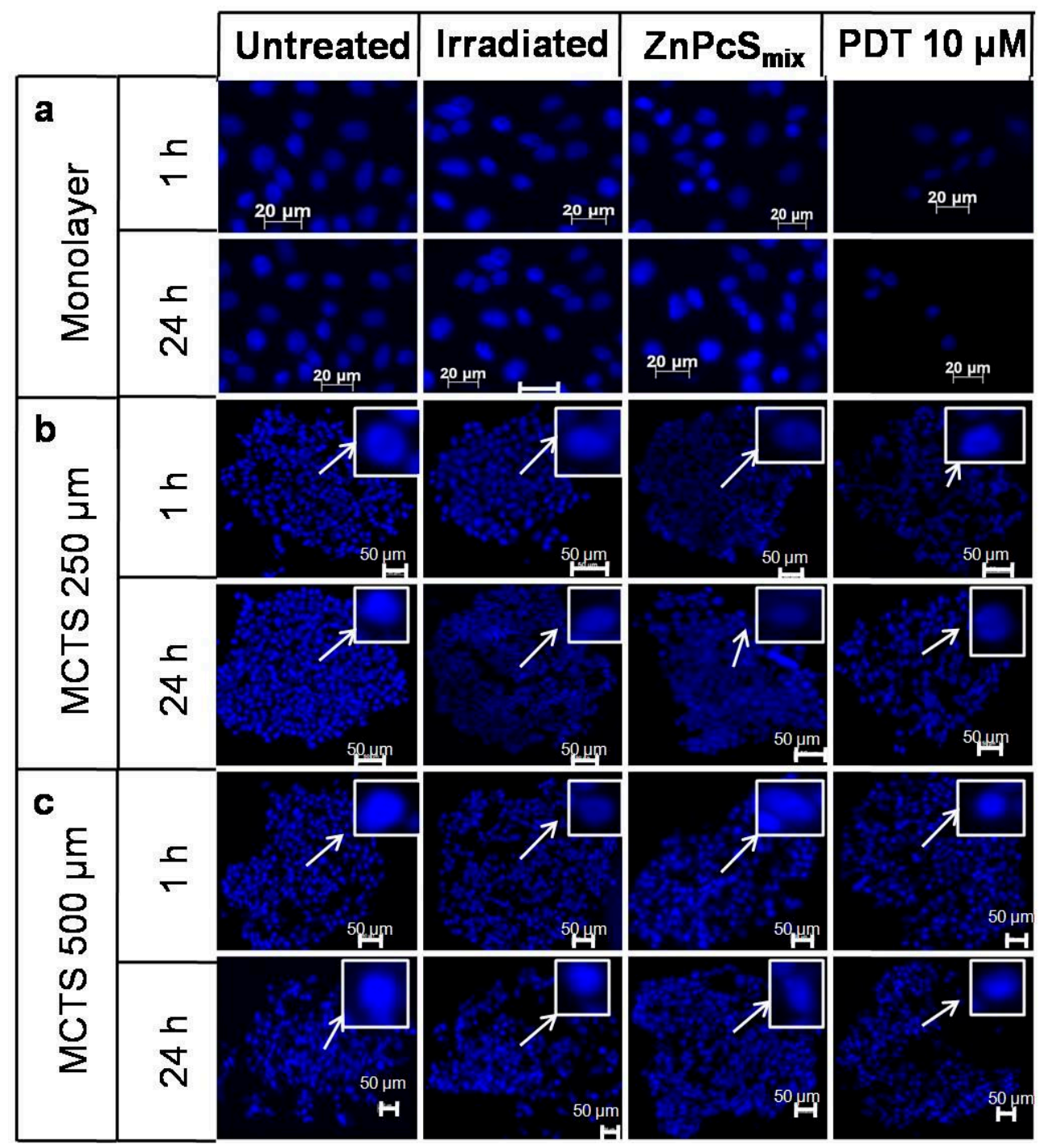

Figure 1. Fluorescence micrograph of monolayer cells (a), multicellular tumour spheroids (MCTSs) with a size of $250 \mu \mathrm{m}(\mathbf{b})$ and MCTSs $(500 \mu \mathrm{m})(\mathbf{c})$ stained with Hoechst 333421 or $24 \mathrm{~h}$ post incubation. Scale bar denotes $50 \mu \mathrm{m}$ in MCTSs. The arrows show enlarged nuclei.

MCTSs $(250 \mu \mathrm{m})$ irradiated with $5 \mathrm{~J} / \mathrm{cm}^{2}$ or incubated with $\mathrm{ZnPcS}$ mix $(10 \mu \mathrm{M})$ alone showed no changes in nuclei morphology when compared to the untreated MCTSs 1 or $24 \mathrm{~h}$ post incubation. However, there was loss of cohesion in the MCTSs $(250 \mu \mathrm{m}) 1$ and $24 \mathrm{~h}$ post PDT. No signs of cell damage, such as apoptosis and necrosis, were seen.

The nuclei of MCTSs $(500 \mu \mathrm{m})$ irradiated with $5 \mathrm{~J} / \mathrm{cm}^{2}$ or incubated with $10 \mu \mathrm{M}$ of $\mathrm{ZnPcS}_{\text {mix }}$ alone appeared similar to that of untreated MCTSs, 1 or $24 \mathrm{~h}$ post PDT. These findings were similar to that 
of monolayer and MCTSs with a size of $250 \mu \mathrm{m}$. There was no loss of cohesion in MCTSs with a size of $500 \mu \mathrm{m} 1$ or $24 \mathrm{~h}$ post PDT. Similarly to that of MCTSs at $250 \mu \mathrm{m}$, there were no signs of apoptosis and necrosis.

\subsection{Real-Time Reverse Transcription Polymerase Chain Reaction (RT-PCR)}

Real-time RT-qPCR was used to determine the genes involved in apoptosis mediated cell death $24 \mathrm{~h}$ after PDT. The Human Apoptosis RT ${ }^{2}$ Profiler PCR Array profiles the expression of 84 key genes involved in programmed cell death. Photoactivated $\mathrm{ZnPcS}_{\operatorname{mix}}(10 \mu \mathrm{M})$ in $\mathrm{A} 549$ monolayer cells resulted in a significant upregulation of the following 10 genes; ABL1, BAG3, BAK1, BCL2L10, BID, CASP5, GADD45A, HRK, TNF, and TP53BP2, and downregulation of three genes-namely: BIRC3, CASP3, and CASP6 (Table 1). Photoactivated $\mathrm{ZnPcS}_{\text {mix }}(10 \mu \mathrm{M})$ in $250 \mu \mathrm{m} \mathrm{MCTSs} \mathrm{showed} \mathrm{upregulation} \mathrm{of}$ only 1 gene (BNIP3), while there was downregulation of 56 genes as described in Table 2. Six genes (BCL2L10, BNIP3, BNIP3L, CD40LG, and IL10) were upregulated, and three genes downregulated (BAX, TNFRSF11B, and TNFRSF21), when $500 \mu \mathrm{m}$ MCTSs were treated with $10 \mu \mathrm{M} \mathrm{ZnPcS}_{\operatorname{mix}}$ and irradiated with a wavelength of $680 \mathrm{~nm}$ at a fluence of $5 \mathrm{~J} / \mathrm{cm}^{2}$ (Table 3).

Table 1. Genes differentially expressed in monolayer A549 cells $24 \mathrm{~h}$ post PDT using the Human Apoptosis RT ${ }^{2}$ Profiler PCR Array system. Upregulated genes had a fold change of greater than 1 , while downregulated genes had a fold change of less than 1 .

\begin{tabular}{cccc}
\hline Gene Symbol & Description & $p$ Value & Fold Change \\
\hline ABL1 & C-abl oncogene 1, non-receptor tyrosine kinase & 0.041 & 1.23 \\
BAG3 & BCL2-associated athanogene 3 & 0.006 & 1.36 \\
BAK1 & BCL2-antagonist/killer 1 & 0.033 & 1.41 \\
BCL2L10 & BCL2-like 10 (apoptosis facilitator) & 0.029 & 1.68 \\
BID & BH3 interacting domain death agonist & 0.035 & 1.20 \\
BIRC3 & Baculoviral IAP repeat containing 3 & 0.023 & -1.94 \\
CASP3 & Caspase 3, apoptosis-related cysteine peptidase & 0.036 & -1.70 \\
CASP5 & Caspase 5, apoptosis-related cysteine peptidase & 0.028 & 2.00 \\
CASP6 & Caspase 6, apoptosis-related cysteine peptidase & 0.045 & -1.16 \\
GADD45A & Growth arrest and DNA-damage-inducible, alpha & 0.005 & 1.43 \\
HRK & Harakiri, BCL2 interacting protein (contains only BH3 domain) & 0.026 & 1.96 \\
TNF & Tumour necrosis factor & 0.008 & 3.57 \\
TP53BP2 & Tumour protein p53 binding protein, 2 & 0.019 & 1.21 \\
\hline
\end{tabular}

Table 2. Genes differentially expressed in $250 \mu \mathrm{m}$ MCTSs $24 \mathrm{~h}$ post PDT using the Human Apoptosis $\mathrm{RT}^{2}$ Profiler PCR Array system. Upregulated genes had a fold change of greater than 1, while downregulated genes had a fold change of less than 1.

\begin{tabular}{cccc}
\hline Gene Symbol & Description & $p$ Value & Fold Change \\
\hline AKT1 & V-akt murine thymoma viral oncogene homolog 1 & 0.005 & -2.71 \\
APAF1 & Apoptotic peptidase activating factor 1 & 0.001 & -1.85 \\
BAD & BCL2-associated agonist of cell death & 0.001 & -1.55 \\
BAG1 & BCL2-associated athanogene & 0.034 & -1.15 \\
BAX & BCL2-associated X protein & 0.000 & -1.34 \\
BCL2 & B-cell CLL/lymphoma 2 & -1.37 \\
BCL2A1 & BCL2-related protein A1 & 0.022 & 0.004 \\
BCL2L1 & BCL2-like 1 & 0.002 & -1.42 \\
BCL2L11 & BCL2-like 11 (apoptosis facilitator) & -1.88 \\
BFAR & Bifunctional apoptosis regulator & 0.001 & -1.35 \\
BID & BH3 interacting domain death agonist & 0.004 & 1.10 \\
BIK & BCL2-interacting killer (apoptosis-inducing) & 0.038 & -1.33 \\
BIRC2 & Baculoviral IAP repeat containing 2 & 0.003 & -1.41 \\
BIRC5 & Baculoviral IAP repeat containing 5 & 0.003 & -1.45 \\
BIRC6 & Baculoviral IAP repeat containing 6 & 0.005 \\
BNIP2 & BCL2/adenovirus E1B 19 kDa interacting protein 2 & 0.010 & -1.13 \\
BNIP3 & BCL2/adenovirus E1B 19 kDa interacting protein 3 & 0.009 & -1.44 \\
BNIP3L & BCL2/adenovirus E1B 19 kDa interacting protein 3-like & 0.009 & -1.09 \\
\hline
\end{tabular}


Table 2. Cont.

\begin{tabular}{|c|c|c|c|}
\hline Gene Symbol & Description & $p$ Value & Fold Change \\
\hline BRAF & V-raf murine sarcoma viral oncogene homolog B1 & 0.001 & -1.48 \\
\hline CASP10 & Caspase 10 , apoptosis-related cysteine peptidase & 0.011 & -1.88 \\
\hline CASP3 & Caspase 3, apoptosis-related cysteine peptidase & 0.012 & -1.31 \\
\hline CASP 4 & Caspase 4 , apoptosis-related cysteine peptidase & 0.000 & -1.14 \\
\hline CASP8 & Caspase 8 , apoptosis-related cysteine peptidase & 0.002 & -1.55 \\
\hline CASP9 & Caspase 9 , apoptosis-related cysteine peptidase & 0.010 & -1.27 \\
\hline CD27 & CD27 molecule & 0.003 & -2.14 \\
\hline CD40 & CD40 molecule, TNF receptor superfamily member 5 & 0.006 & -1.31 \\
\hline CD40LG & CD40 ligand & 0.022 & -1.80 \\
\hline CD70 & CD70 molecule & 0.001 & -1.33 \\
\hline CFLAR & CASP8 and FADD-like apoptosis regulator & 0.007 & -1.23 \\
\hline CIDEA & Cell death-inducing DFFA-like effector a & 0.012 & -1.91 \\
\hline CIDEB & Cell death-inducing DFFA-like effector $b$ & 0.014 & -1.89 \\
\hline CYCS & Cytochrome c, somatic & 0.002 & -1.92 \\
\hline DAPK1 & Death-associated protein kinase 1 & 0.002 & -1.50 \\
\hline DFFA & DNA fragmentation factor, $45 \mathrm{kDa}$, alpha polypeptide & 0.019 & -1.30 \\
\hline DIABLO & Diablo, IAP-binding mitochondrial protein & 0.028 & -1.17 \\
\hline FADD & Fas (TNFRSF6)-associated via death domain & 0.032 & -1.58 \\
\hline FASLG & Fas ligand (TNF superfamily, member 6) & 0.023 & -2.03 \\
\hline GADD45A & Growth arrest and DNA-damage-inducible, alpha & 0.034 & -1.36 \\
\hline IGF1R & Insulin-like growth factor 1 receptor & 0.005 & -1.87 \\
\hline IL10 & Interleukin 10 & 0.032 & -2.02 \\
\hline LTBR & Lymphotoxin beta receptor (TNFR superfamily, member 3) & 0.001 & -1.15 \\
\hline MCL1 & Myeloid cell leukemia sequence 1 (BCL2-related) & 0.000 & -1.35 \\
\hline NAIP & NLR family, apoptosis inhibitory protein & 0.000 & -1.75 \\
\hline NFKB1 & Nuclear factor of kappa light polypeptide gene enhancer in B-cells 1 & 0.022 & -1.25 \\
\hline NOL3 & Nucleolar protein 3 (apoptosis repressor with CARD domain) & 0.004 & -1.15 \\
\hline TNFRSF10A & Tumour necrosis factor receptor superfamily, member $10 \mathrm{a}$ & 0.038 & -1.92 \\
\hline TNFRSF10B & Tumour necrosis factor receptor superfamily, member $10 \mathrm{~b}$ & 0.025 & -1.95 \\
\hline TNFRSF1A & Tumour necrosis factor receptor superfamily, member $1 \mathrm{~A}$ & 0.006 & -1.34 \\
\hline TNFRSF25 & Tumour necrosis factor receptor superfamily, member 25 & 0.016 & -2.02 \\
\hline TNFSF10 & Tumour necrosis factor (ligand) superfamily, member 10 & 0.000 & -2.10 \\
\hline TNFSF8 & Tumour necrosis factor (ligand) superfamily, member 8 & 0.020 & -1.83 \\
\hline TP53 & Tumour protein p53 & 0.045 & -1.42 \\
\hline ТР53ВР2 & Tumour protein p53 binding protein, 2 & 0.001 & -1.21 \\
\hline TP73 & Tumour protein p73 & 0.030 & -2.43 \\
\hline TRADD & TNFRSF1A-associated via death domain & 0.001 & -1.52 \\
\hline TRAF3 & TNF receptor-associated factor 3 & 0.038 & -1.26 \\
\hline XIAP & X-linked inhibitor of apoptosis & 0.000 & -1.61 \\
\hline
\end{tabular}

Table 3. Genes differentially expressed in $500 \mu \mathrm{m}$ MCTSs $24 \mathrm{~h}$ post PDT using the Human Apoptosis $\mathrm{RT}^{2}$ Profiler PCR Array system. Upregulated genes had a fold change of greater than 1 , while downregulated genes had a fold change of less than 1.

\begin{tabular}{cccc}
\hline Gene Symbol & Description & $p$ Value & Fold Change \\
\hline BAX & BCL2-associated X protein & 0.046 & -1.27 \\
BCL2L10 & BCL2-like 10 (apoptosis facilitator) & 0.034 & 1.09 \\
BNIP3 & BCL2/adenovirus E1B 19 kDa interacting protein 3 & 0.001 & 1.71 \\
BNIP3L & BCL2/adenovirus E1B 19 kDa interacting protein 3-like & 0.001 & 1.74 \\
CD40LG & CD40 ligand & 0.023 & 2.76 \\
FASLG & Fas ligand (TNF superfamily, member 6) & 0.030 & 3.52 \\
IL10 & Interleukin 10 & 0.000 & 3.54 \\
TNFRSF11B & Tumour necrosis factor receptor superfamily, member 11b & 0.004 & -1.56 \\
TNFRSF21 & Tumour necrosis factor receptor superfamily, member 21 & 0.022 & -1.20 \\
\hline
\end{tabular}

\section{Discussion}

\subsection{Gene Expression Profiling in the Monolayer Cultures}

Two-dimensional monolayer cell cultures do not adequately represent an in vivo environment, while three-dimensional culture systems, such as MCTSs, better resemble in vivo tumour phenotypes, 
and are gradually becoming a more suitable model for the screening of anti-cancer drugs and development of new therapeutic interventions [22]. In our previous studies, we demonstrated that lung cancer MCTSs, with a size of $250 \mu \mathrm{m}$, were more susceptible to PDT than monolayer cell cultures [21], while MCTSs with a size of $500 \mu \mathrm{m}$ were resistant to PDT [16]. The principal mechanism of PDT induced cell death in both studies was apoptosis. During PDT induced apoptotic cell death, expression of genes and their proteins are altered [20]. The present study used the SABiosciences Human Apoptosis $\mathrm{RT}^{2}$ Profiler PCR Array to determine the expression of 84 key genes involved in apoptosis in A549 cells grown as a monolayer and as MCTSs (250 and $500 \mu \mathrm{m}) 24 \mathrm{~h}$ post PDT to determine the mechanisms involved in apoptotic cell death.

Gene expression profiling $24 \mathrm{~h}$ post PDT revealed differential genetic expression profiles in monolayer cells versus MCTSs $(250$ and $500 \mu \mathrm{m})$. These results suggest different mechanisms in the apoptotic cell death of A549 cells grown as a monolayer and as MCTSs. Gene expression profiling in monolayer cells revealed the upregulation of eight pro-apoptotic genes-namely ABL1, BAK1, BID, CASP5, GADD45A, HRK, TNF, TP53BP2 - and downregulation of two pro-apoptotic genes (CASP3 and CASP6). Anti-apoptotic genes that were upregulated were BAG3 and BCL2L10, while BIRC3 was downregulated. From these results, it was clear that the genes which were predominantly over expressed were pro-apoptotic, correlating with the results found in our previous study, using Annexin V-FITC, which revealed apoptotic cell death in monolayer A549 cells post PDT [21].

Tissue necrosis factor 'TNF', which triggers the extrinsic apoptotic pathway, was upregulated in the monolayer cultured cells. TNF induces apoptosis by binding to its cognate receptors belonging to the TNF receptor 'TNFR' family [23]. This leads to the formation of cytosolic signalling complexes which initiate apoptosis signalling. Subsequently, Fas-associated death domain 'FADD' and inactive caspase- 8 join, resulting in the formation of complex II. The presence of several molecules of caspase- 8 in complex II leads to proximity activation of these signalling proteins. Activated caspase- 8 cleaves and activates executioner caspases which in turn cleave multiple substrates resulting in apoptotic cell death $[23,24]$. Although TNF is involved in autophagy, deficient mechanisms can result in over activation c-Jun N-terminal kinase ' $\mathrm{JNK}^{\prime}$ ', which increases caspase-8 activation, and allows for the initiation of TNF-dependent apoptosis.

BH3 interacting domain death agonist 'BID' is a pro-apoptotic gene that encodes a death agonist that heterodimerizes with either agonist BAX or antagonist BAK, BCL-2 family members. Activated BAX/BAK causes outer mitochondrial membrane permeabilisation 'MOMP', which results in the cytosolic release of apoptogenic factors — such as cytochrome $c$ and Smac/DIABLO-that cause activation of the caspase cascade. A study conducted using zinc phthalocyanine PDT in human MCF-7c3 breast cancer cells demonstrated PDT induced BID activation [24].

BAG3 is a member of the BAG family of co-chaperones that influences cell survival by interacting with different molecular partners, and hence activating multiple pathways. BAG3 can potently suppress cell apoptosis via its interaction with Hsp70, a chaperone protein able to temper apoptosis by interfering with cytochrome c release, apoptosome formation, and other events involved in cell death. Recent reports have shown additional functions of this chaperone in the regulation of autophagy [25]. However, in this study, the upregulation of this gene was not sufficient in blocking apoptosis. BCL-2 antagonist/killer 1 'BAK1', in the presence of an appropriate stimulus, may promote apoptosis by antagonizing the anti-apoptotic action of BCL-2 [26]. In our study, BAK1 upregulation resulted in the inhibition of BCL-2, thereby with subsequent apoptosis.

The growth arrest and DNA damage inducible gene 45 alpha GADD $45 \alpha$ is a stress signal response gene that, although its exact mechanism is not fully understood, is involved in regulating DNA repair and apoptosis. The GADD45 family members interact with the upstream kinase MTK1/MEKK4 when exposed to environmental stresses, which results in apoptosis through the p38/JNK pathways [27]. A study by Yin et al. (2004) demonstrated apoptotic cell death in human MCF-7 breast cancer cells exposed to troglitazone when the GADD45 gene was upregulated [28]. Another study by Chang et al. (2013) demonstrated that 2-methoxyestradiol (2-ME), an oestrogen metabolite, induces mitochondrial 
mediated apoptosis by the upregulation of HRK. HRK is involved in the 2-ME-induced apoptotic pathway by activating caspase through BAK-mediated cytochrome c release [29]. Our present study yielded similar results in the A549 cells showing upregulation of GADD45 and subsequent apoptosis of cells.

Tumour protein p53 binding protein 2 'TP53BP2' p53 induces the expression of genes such as BAX and other BCL-2 family members that promote the release of cytochrome $\mathrm{c}$ into the cytoplasm from mitochondria and initiate the intrinsic apoptotic pathway. Tumour protein p53, depending on its origin, however, may have various effects on the regulation of autophagy. Cytoplasmic p53 inhibits autophagy, while nuclear p53 activates autophagy. The present study demonstrated upregulation of TP53BP2 which codes for $\mathrm{p} 53$ (TP53BP2 specifically regulates p53-dependent apoptosis), in combination with other pro-apoptotic genes, and therefore inducing apoptosis [30]. Ye et al. (2015) demonstrated the role of p53 in apoptosis of MCF-7 cells [31], and the findings confer with what was demonstrated in our study, where p53 was upregulated and cells underwent apoptotic cell death.

BIRC3 encodes a member of the IAP family of proteins that inhibit apoptosis by binding to TNFR associated factors. Kumari et al. (2007) showed that the PS 5-Aminolevulinic acid (5-ALA) induces apoptosis in human glioblastoma U87MG cells by downregulation of BIRC 3 and activation of calpain, caspase-9, and caspase-3 [32]. However, the latter were also found to be downregulated in our study, as well as caspase- 6 . This is suggestive that the apoptotic cell death observed might follow a caspase independent cell death pathway. The altered expression of genes belonging to the BCL2 family, and TNF signalling in monolayer cells, suggests that there is involvement of both intrinsic and extrinsic apoptotic pathways (Figure 2).

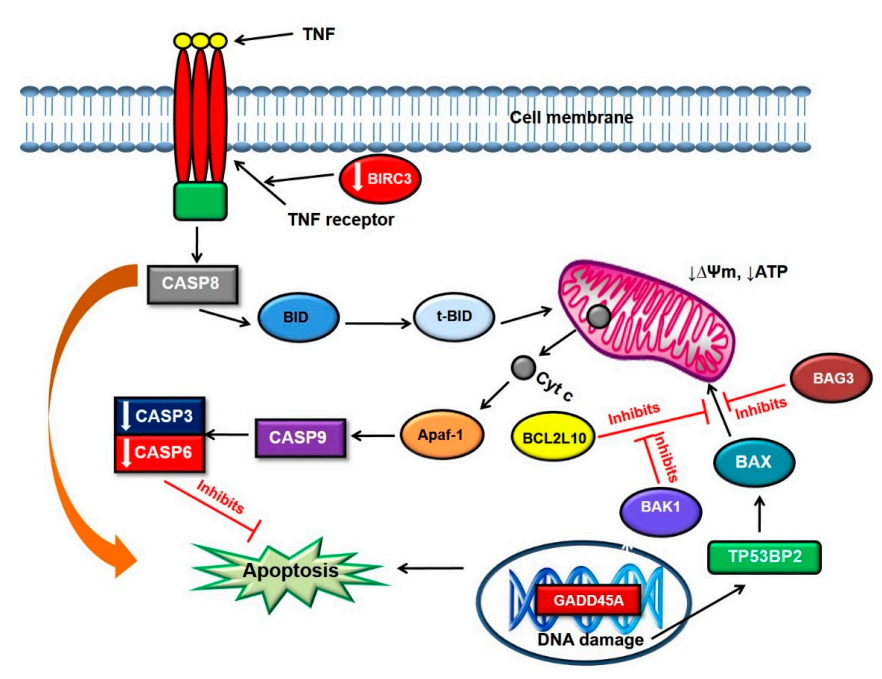

Figure 2. Possible apoptotic pathway induced by photoactivated $\mathrm{ZnPcS}_{\text {mix }}$ in monolayer cells $24 \mathrm{~h}$ post PDT. TNF triggers the extrinsic apoptotic pathway by binding to the TNF receptor and initiating the caspase cascade. CASP8 can directly induce apoptosis or cleave BID into truncated Bid which translocates to the mitochondria. In the mitochondria, BID can result in the release of cytochrome $\mathrm{C}$ (cyt c) which activates CASP9 and eventually CASP3. However, in this study, CASP3 and CASP6 were downregulated. BCL2L10 blocks apoptosis induced BAX which in turn is antagonized by BAK 1 .

\subsection{Gene Expression Profiling in the MCTSs}

MCTSs with a size of $250 \mu \mathrm{m}$ revealed upregulation of only 2 genes $24 \mathrm{~h}$ post PDT; BCL2/adenovirus E1B $19 \mathrm{kDa}$ interacting protein 3 'BNIP3', and BCL2-related protein A1 'BCL2A1', while there was downregulation of 56 genes (Table 2). BNIP3 is a pro-apoptotic gene capable of homodimerization and heterodimerization with the anti-apoptotic protein BCL2. Activation of BNIP3 leads to localization of BNIP3 in the mitochondria where it causes mitochondrial dysfunction and eventually cell death [33]. Due to their 3D structure, spheroids contain mass-transfer gradients of 
oxygen and nutrient waste. These metabolic gradients drive proliferation gradients and given sufficient cell numbers and time in culture, spheroids can develop hypoxic cores that can progress to necrosis, closely mimicking what is observed in vivo. BNIP3 expression is highly elevated in hypoxic conditions and PDT is known to induce hypoxia [34]. Growing cancer cells as MCTSs also creates hypoxic conditions in the inner core of the MCTS [35]. A combination of PDT and growing cells as MCTSs might have contributed to the upregulation of the BNIP3 gene in this study. A study conducted by Guo et al. (2001) demonstrated that the over expression of BNIP3 causes apoptotic cell death through a mechanism that does not involve activation of caspase-3 or -9 or cytochrome c release [36]. ROS has also been shown to cause direct activation of BNIP3, and ROS produced after PDT in this study might have contributed to the elevation of BNIP3 [37].

In our previous study, MCTSs with a size of $250 \mu \mathrm{m}$ showed the highest loss of membrane integrity as revealed by the results of flow cytometry using Annexin V-FITC [21]. It is possible that, in the present study, PDT induced BNIP3 mediated apoptotic cell death in MCTSs with a size of $250 \mu \mathrm{m}$, since it was the only gene that was upregulated. BNIP3 may also be associated with mitophagy, but the function of mitophagy during apoptosis has not been resolved. Firstly, mitochondrial outer membrane permeabilization (MOMP) occurs within minutes once activated, whereas mitophagy occurs progressively and secondly, following MOMP, apoptotic caspases inactivate the autophagy induction machinery limiting autophagy induction capacity. Buyen et al. (2011) also demonstrated BNIP3 mediated apoptotic cell death in HT29 cells treated with a chemotherapeutic drug (Cisplatin) [38].

BCL2A1 is an ant-apoptotic gene found to be expressed by proteins in the mitochondrial membrane. Although little is known on how it functions, the pro-survival mechanism can be inhibited [39]. BCL-2, although known to block apoptosis, can promote cell death through an undefined mechanism. BCL-2 has been shown to interact with orphan nuclear receptor 'Nur77', which is required for cancer cell apoptosis and can be induced by many anti-neoplastic agents. This interaction results in the conversion of BCL-2 from a protector to a killer, resulting in apoptotic cell death [40].

In this study, the genes that are known to promote apoptotic cell death were downregulated in MCTSs $(250 \mu \mathrm{m}) 24 \mathrm{~h}$ post PDT (Table 2$)$. However, upregulation of one pro-apoptotic gene (BNIP3), and the interaction with Nur77, the only anti-apoptotic gene, as described above, induced apoptotic cell death (Figure 3). The downregulation of all anti-apoptotic genes resulted in no genes opposing the pro-apoptotic stimuli induced by BNIP3, thereby rendering cells susceptible to apoptotic cell death.

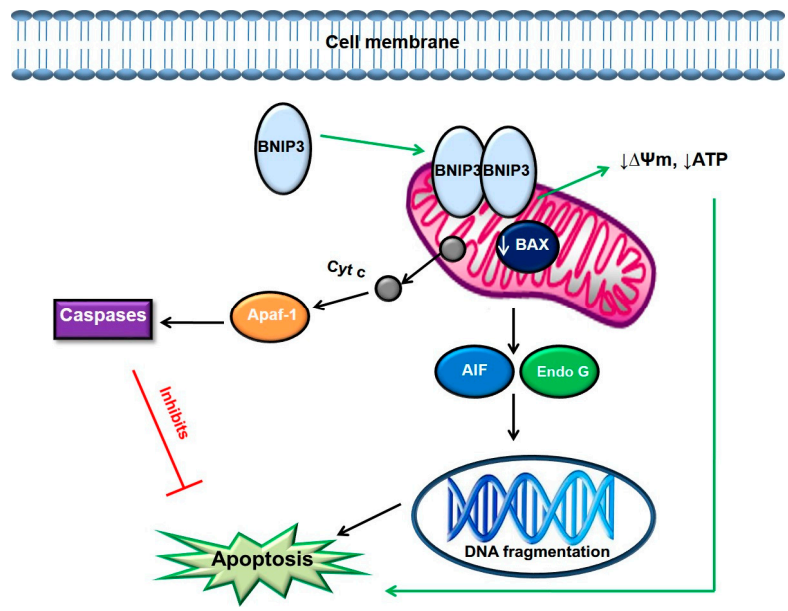

Figure 3. Possible apoptotic pathway induced by photoactivated $\mathrm{ZnPcS}_{\text {mix }}$ in MCTSs $24 \mathrm{~h}$ post PDT. BNIP3 induces apoptosis by dimerization and inserting into the mitochondria. In the mitochondria, BNIP3 can interact with BAX resulting in the permeabilization of the mitochondrial outer membrane which may directly cause apoptosis. Alternatively, permeabilization of the membrane may result in the release of cyt c which activates caspases. However, in this study, gene expression profiling revealed downregulation of caspases, therefore apoptosis was independent of caspases. 
In MCTSs with a diameter of $500 \mu \mathrm{m}$, there was upregulation of only one pro-apoptotic gene (BNIP3) and downregulation of three pro-apoptotic genes-namely BAX, TNFRSF11B, and TNFRSF21. Anti-apoptotic genes that were upregulated were BCL2L10, BNIP3L, CD40LG, and IL10, and there was no downregulation of anti-apoptotic genes. These results suggest that MCTS with a diameter of $500 \mu \mathrm{m}$ were more resistant to apoptosis. Since BNIP3 was the only pro-apoptotic gene that was upregulated following PDT, the apoptotic cell death seen in MCTSs $(500 \mu \mathrm{m})$ might be as a result of this gene.

As seen in the smaller MCTSs $(250 \mu \mathrm{m})$, MCTSs with a diameter of $500 \mu \mathrm{m}$ also underwent a BNIP3 mediated apoptotic cell death (Figure 2). BNIP3 may also lead to autophagy, however, the mechanism in which it does so is not fully understood [36]. Quinsay et al. (2010) showed that over expression of BNIP3 causes mitochondrial dysfunction and removal of the mitochondria by auto-phagosomes in adult cardiac myocytes [39]. BNIP3 interacts with BCL2, leading to cell death which is not dependent on the $\mathrm{BH} 3$ domain thought to be responsible for causing pro-apoptotic activity in other $\mathrm{BH} 3$ containing proteins [41].

Interleukin 10 (IL10) is an anti-inflammatory cytokine that prevents the production of cytokines in antigen presenting cells and activated T-cells. It prevents apoptosis by downregulating pro-apoptotic BAX and upregulation of BCL2 [42]. In our study, the downregulation of BAX and upregulation of BCL2 might have been regulated by IL10. A study by Gollnick et al. (1997) showed increased expression of IL10 in skin of mice treated with porfirmer and a $630 \mathrm{~nm}$ argon laser, suggesting that IL10 plays a role in cell mediated responses following PDT [43]. Byun et al. (2011) also showed increased expression of IL10 which contributed to the anti-inflammatory effects after PDT in normal human fibroblasts [38].

Nuclear factor kappa B (NF-kB) is implicated in both the suppression and activation of apoptosis. Tumour necrosis factor superfamily member 21 (TNFRSF21) is a pro-apoptotic gene and a member of the TNF-receptor superfamily [44]. Activation of TNFRSF21 in some cell lines leads to apoptosis and activation of the c-Jun N-terminal protein kinase (JNK) and NF- $\mathrm{B}$ p pathways which induces apoptosis [45]. The downregulation of TNF superfamily members suggests that PDT did not induce the extrinsic apoptotic pathway in MCTSs.

\section{Materials and Methods}

\subsection{Monolayer Cell Culture}

A human lung cancer cell line (A549, $\left.\mathrm{ATCC}^{\circledR} \mathrm{CCL}-185\right)$ was grown in Rosewell Park Memorial Institute 1640 medium (RPMI, Life Technologies, Invitrogen, Johannesburg, South Africa), supplemented with 10\% foetal bovine serum (FBS, Gibco, Johannesburg, South Africa), 0.5\% penicillin/streptomycin (Gibco) and 0.5\% amphotericin-B antifungal (Gibco). Cells were cultured at $37^{\circ} \mathrm{C}$ and $5 \% \mathrm{CO}_{2}$ at $85 \%$ humidity.

\subsection{MCTS Cell Culture}

The formation of lung cancer spheroids was initiated by culturing $5 \times 10^{4}$ A549 cells in $75 \mathrm{~cm}^{2}$ culture flasks, coated with 1\% low melting agarose (Sigma Aldrich, Johannesburg, South Africa). After three days, the resulting aggregates were transferred to $250 \mathrm{~mL}$ spinner flasks (Integra Biosciences, Johannesburg, South Africa) containing $150 \mathrm{~mL}$ of culture medium. The flasks were placed on a magnetic spinner plate operating at $75 \mathrm{rpm}$ in an incubator set at $37{ }^{\circ} \mathrm{C}$ with $5 \% \mathrm{CO}_{2}$ and $85 \%$ humidity. MCTS culture medium was changed three times weekly by allowing the spheroids to settle to the bottom of the spinner flask, carefully removing $100 \mathrm{~mL}$ of the medium and replacing with fresh supplemented medium. When spheroids reached approximately $250 \mu \mathrm{m}$ in diameter, usually after 10 days, and $500 \mu \mathrm{m}$ diameter after 14 days, they were used for experiments. 


\subsection{Photodynamic Treatment of Monolayer Cells}

Once A549 cells were 80\% confluent, they were harvested and seeded into $3.4 \mathrm{~cm}$ diameter culture dishes for experimental purposes, at a concentration of $2 \times 10^{5}$ cells per culture dish. Cells were allowed to attach to culture dishes for $4 \mathrm{~h}$ before incubating with zinc sulfophthalocyanine $\left(\mathrm{ZnPcS}_{\operatorname{mix}}\right)$ at a concentration of $10 \mu \mathrm{M}$ for $24 \mathrm{~h}$. Prior to laser irradiation, cells were washed twice with Hanks Balanced Salt Solution (HBSS, Invitrogen, Johannesburg, South Africa) to remove any unabsorbed $\mathrm{ZnPcS}_{\text {mix }}$ and fresh media was added. Cells were irradiated using a diode laser emitting at a wavelength of $680 \mathrm{~nm}$ and a fluence of $5 \mathrm{~J} / \mathrm{cm}^{2}$, supplied by the National Laser Centre 'NLC' South Africa. All laser irradiations were performed in the dark. The light beam was delivered from the top of the culture dish, with the culture dish lid removed, via fibre optics. Laser irradiation parameters are shown in Table 4. Cells were further incubated, at $37{ }^{\circ} \mathrm{C}$ with $5 \% \mathrm{CO}_{2}$ and $85 \%$ humidity, for $24 \mathrm{~h}$ before real-time reverse transcription quantitative polymerase chain reaction (RT-PCR) arrays were carried out.

Table 4. Laser irradiation parameters used in this study.

\begin{tabular}{|c|c|}
\hline Parameters & Description/Value \\
\hline Manufacturer & Oriel Corporation, USA \\
\hline Wavelength (nm) & 680 \\
\hline Wave emission & Continuous wave \\
\hline Power output (mW) & 44.2 \\
\hline Power density $\left(\mathrm{mW} / \mathrm{cm}^{2}\right)$ & 4.87 \\
\hline Spot size $\left(\mathrm{cm}^{2}\right)$ & 9.1 \\
\hline Fluence $\left(\mathrm{J} / \mathrm{cm}^{2}\right)$ & 5 \\
\hline Duration of exposure & $17 \min 7 \mathrm{~s}$ \\
\hline
\end{tabular}

\subsection{Photodynamic Treatment of MCTS}

Fifty A549 spheroids were transferred from spinner flasks to $3.4 \mathrm{~cm}$ diameter culture dishes. Spheroids were incubated for $24 \mathrm{~h}$ with $\mathrm{ZnPcS}_{\mathrm{mix}}$ at a concentration of $10 \mu \mathrm{M}$. Spheroids were then washed twice in HBSS before laser irradiation and irradiated in the same manner as the monolayer cells above.

\subsection{Nuclear Morphology}

Monolayer cells were seeded onto heat sterilized coverslips in cell culture dishes and treated as in Section 4.3 and incubated 1 or 24 h post PDT. The monolayer cells were stained with Hoechst 33342 $(1 \mu \mathrm{M})$ by incubation in dye containing growth medium at $37^{\circ} \mathrm{C}$ for $5 \mathrm{~min}$. Coverslips were then mounted on a glass slide and fluorescence was visualized as before.

Cryosections of MCTS were prepared by collecting five spheroids using a pipette and placed in $1 \%$ eosin stain in order to see the spheroids during sectioning. Spheroids were then washed three times with phosphate buffered saline to remove excess stain. A small amount of shandon cryomatrix was placed on the center of a cryomold and then place inside a cryostat set at $-20^{\circ} \mathrm{C}$ in order to freeze the shandon cryomatrix. Once the shandon cryomatrix had frozen, spheroids were placed on top of the frozen shandon cryomatrix and then another drop of shandon cryomatrix was placed on top of the spheroids. Once the shandon cryomatrix had frozen, the block was the mounted on a cryostat and sectioned at $10 \mu \mathrm{m}$. Cryosections were placed on microscope slides and stained with Hoechst 33342 for $5 \mathrm{~min}, 1 \mathrm{~h}$ or $24 \mathrm{~h}$ post PDT.

\subsection{RNA Isolation and cDNA Synthesis}

Total RNA was isolated and purified using the RNeasy Mini Kit (Whitehead Scientific, Qiagen, Johannesburg, South Africa, 74104) with the QIAshredder homogenizers (Whitehead Scientific, Qiagen, 79654). Cells were detached from culture dishes using TrypLE ${ }^{\mathrm{TM}}$ Express (Life Technologies, 
Johannesburg, South Africa, Gibco, Invitrogen, 12605-028) and washed in phosphate buffered saline (PBS) in order to remove all traces of cell culture medium. Cells were lysed with $600 \mu \mathrm{L}$ RLT buffer, which also inactivates RNases, to ensure purification of the intact RNA. The lysed cells were then loaded onto the QIAcube (Qiagen) with the subsequent release of $30 \mu \mathrm{L}$ of RNA in under $30 \mathrm{~min}$. Isolated RNA was quantified on the Qubit fluorometer (Invitrogen) using the Quant-iT RNA assay kit (Applied Biosystems, Johannesburg, South Africa, Invitrogen, Q32852). The ratio between the absorbance values at 260 and $280 \mathrm{~nm}\left(\mathrm{~A}_{260 \mathrm{~nm}} / \mathrm{A}_{280 \mathrm{~nm}}\right)$ was used to estimate RNA purity using a UV/Vis spectrophotometer. cDNA was synthesized using the QuantiTect Reverse Transcription Kit (Whitehead Scientific, Cape town, South Africa, Qiagen) from $1 \mu \mathrm{g}$ total RNA. Briefly, samples were treated with gDNA wipe-out buffer and incubated for $2 \mathrm{~min}$ at $42{ }^{\circ} \mathrm{C}$. Reverse transcription (RT) master mix was added and samples were incubated for $15 \mathrm{~min}$ at $4{ }^{\circ} \mathrm{C}$, and thereafter, $3 \mathrm{~min}$ at $95^{\circ} \mathrm{C}$ to terminate the reaction. cDNA was stored at minus $20^{\circ} \mathrm{C}$ until real time PCR was run.

\subsection{Gene Expression Profiling}

Quantitative Real-Time RT-PCR was performed using the Human Apoptosis RT ${ }^{2}$ Profiler PCR Array (Whitehead Scientific, Johannesburg, South Africa, SABiosciences, PAHS-012Z) which profiles the expression of 84 key genes involves in apoptotic cell death (Table 5). cDNA was thawed on ice and $18 \mu \mathrm{L}$ of cDNA was added to $93 \mu \mathrm{L}$ of PCR water, making up the total volume to $111 \mu \mathrm{L}$. RT-PCR was performed on the Stratagene MX3000p and a two-step cycling protocol was set on the instrument; $10 \mathrm{~min}$ at $95^{\circ} \mathrm{C}$ followed by 40 cycles of $15 \mathrm{~s}$ at $95^{\circ} \mathrm{C}$ and $1 \mathrm{~min}$ at $60^{\circ} \mathrm{C}$. A dissociation (melting) curve program was performed using the following parameters; $95{ }^{\circ} \mathrm{C}$ for $1 \mathrm{~min}, 55^{\circ} \mathrm{C}$ for $30 \mathrm{~s}$, and $55^{\circ} \mathrm{C}$ to $95{ }^{\circ} \mathrm{C}$ at a rate of $2{ }^{\circ} \mathrm{C}$ per min. Threshold cycle ' $\mathrm{C}_{\mathrm{t}}$ ' values were exported to an Excel-based Data Analysis Template (available from the SABiosciences website) with the appropriate pathway-focused genes. The $C_{t}$ values of the control and the genes of interest 'GOI' were normalized to appropriate endogenous housekeeping ' $H K^{\prime}$ genes. The $2^{(-\Delta \Delta \mathrm{Ct})}$ comparative method was used to determine the fold changes in gene expression between the control (untreated) and PDT treated experimental groups. This was done by comparing the $C_{t}$ values of the samples of interest (PDT treated) with the control i.e., $\Delta \Delta \mathrm{C}_{\mathrm{t}}=\Delta \mathrm{C}_{\mathrm{t}}$ sample $\left(\mathrm{GOI}_{\text {treated }}-\mathrm{HKG}_{\text {treated }}\right)-\Delta \mathrm{C}_{\mathrm{t}}$ control $\left(\mathrm{GOI}_{\text {control }}-\mathrm{HKG}_{\text {control }}\right)$. Therefore, normalized target gene expression level, or fold change, is $2^{(-\Delta \Delta C t)}$. Fold change values greater than 1 indicate an upregulated gene, while values less than 1 indicate a downregulated gene (Table 5).

Table 5. Functional grouping of the SABiosciences Human Apoptosis RT ${ }^{2}$ Profiler PCR Array.

\begin{tabular}{cl}
\hline \multicolumn{1}{c}{ Pathway } & \multicolumn{1}{c}{ Genes } \\
\hline Induction of apoptosis: & \\
\hline Death domain receptors & CRADD, FADD, TNF, TNFRSF10B (DR5) \\
\hline DNA damage & ABL1, CIDEA, CIDEB, TP53, TP73 \\
\hline Extracellular signals & CFLAR (CASPER), DAPK1, TNFRSF25 (DR3) \\
\hline & BAD, BAK1, BAX, BCL10, BCL2L11, BID, BIK, BNIP3, BNIP3L, CASP1 (ICE), CASP10 \\
(MCH4), CASP14, CASP2, CASP3, CASP4, CASP6, CASP8, CD27 (TNFRF7), CD70 (TNFSF7), \\
Cther & CYCS, DFFA, DIABLO (SMAC), FAS (TNFRSF6), FASLG (TNFSF6), GADD45A, HRK, LTA \\
& (TNFB), NOD1 (CARD4), PYCARD (TMS1/ASC), TNFRSF10A, TNFRSF9, TNFSF10 (TRAIL), \\
& TNFSF, TP53BP2, TRADD, TRAF3 \\
\hline \multirow{4}{*}{ Anti-apoptosis: } & BKT1, BAG1, BAG3, BAX, BCL2, BCL2A1 (Bfl-1/A1), BCL2L1 (BCL-X), BCL2L10, BCL2L2, \\
& CD40LG (TNFSF5), CFLAR (CASPER), DAPK1, FAS (TNFRSF6), HRK, IGF1R, IL10, MCL1, \\
& NAIP (BIRC1), NFKB1, NOL3, RIPK2, TNF, XIAP (BIRC4) \\
\hline
\end{tabular}


Table 5. Cont.

\begin{tabular}{|c|c|}
\hline Pathway & Genes \\
\hline \multicolumn{2}{|l|}{ Regulation of apoptosis: } \\
\hline Negative regulation & $\begin{array}{l}\text { BAG1, BAG3, BCL10, BCL2, BCL2A1 (Bfl-1/A1), BCL2L1 (BCL-X), BCL2L10, BCL2L2, BFAR, } \\
\text { BIRC2 (c-IAP2), BIRC3 (c-IAP1), BIRC6, BNIP2, BNIP3, BNIP3L, BRAF, CASP3, CD27 } \\
\text { (TNFRS7), CD40LG (TNFSF5), CFLAR (CASPER), CIDEA, DAPK1, DFFA, FAS (TNFRSF6), } \\
\text { IGF1R, MCL1, NAIP (BIRC1), NOL3, TP53, TP73, XIAP (BIRC4) }\end{array}$ \\
\hline Positive regulation & $\begin{array}{l}\text { ABL1, AKT1, BAD, BAK1, BAX, BCL2L11, BID, BIK, BNIP3, BNIP3L, CASP1 (ICE), CASP10 } \\
\text { (MCH4), CASP14, CASP2, CASP4, CASP6, CASP8, CD40 (TNFRSF5), CD70 (TNFSF7), CIDEB, } \\
\text { CRADD, FADD, FASLG (TNFSF6), HRK, LTA (TNFB), LTBR, NOD1 (CARD4), PYCARD } \\
\text { (TMS1 / ASC), RIPK2, TNF, TNFRSF10A, TNFRS10B (DR5), TNFRF25 (DR3), TNFRSF, } \\
\text { TNFSF10 (TRAIL), TNFSF8, TP53, TP53BP2, TRADD, TRAF2, TRAF3 }\end{array}$ \\
\hline Death domain proteins: & $\begin{array}{l}\text { CRADD, DAPK1, FADD, TNFRSF10A, TNFRSF10B (DR5), TNFRSF11B, TNFRSF1A, } \\
\text { TNFRSF1B, TNFRSF21, TNFRSF25 (DR3), TRADD }\end{array}$ \\
\hline \multicolumn{2}{|l|}{ Caspases and regulators: } \\
\hline Caspases & $\begin{array}{l}\text { CASP1 (ICE), CASP10 (MCH4), CASP14, CASP2, CASP3, CASP4, CASP5, CASP6, CASP7, } \\
\text { CASP8, CASP9, CFLAR (CASPER), CRADD, PYCARD (TMS1 / ASC) }\end{array}$ \\
\hline Caspase activators & $\begin{array}{l}\text { AIFM1 (PDCD8), APAF1, BAX, BCL2L10, CASP1 (ICE), CASP9, NOD1 (CARD4), PYCARD } \\
\text { (TMS1 / ASC), TNFRSF10A, TNFRSF10B (DR5), TP53 }\end{array}$ \\
\hline Caspase inhibitors & CD27 (TNFRSF7), XIAP (BIRC4) \\
\hline Housekeeping genes: & ACTB, B2M, GAPDH, HPRT1, RPLP0 \\
\hline
\end{tabular}

\section{Statistical Analysis}

Experiments were repeated three times $(n=3)$. The Student $t$ test was performed by the SABiosciences Excel-based Data Analysis Template, and results were reported as significant if $p<0.05$.

\section{Conclusions}

The study aimed at identifying which apoptotic genes were involved in cell death of lung cancer cells grown in monolayer versus those grown as tumour spheroids, following photodynamic therapy using a novel photosensitizer $\left(\mathrm{ZnPcS}_{\text {mix }}\right)$. This was assessed by measuring the up and downregulation of genes in an apoptotic cell death pathway PCR array. Gene expression analysis showed that photoactivated $\mathrm{ZnPcS}_{\text {mix }}$ in monolayer cultured cells induced apoptosis through the upregulation of various pro-apoptotic genes, while in MCTSs (with a diameter of 250 and $500 \mu \mathrm{m}$ ), apoptosis was induced through the upregulation of only one gene (BNIP3). In the $250 \mu \mathrm{m}$ MCTSs, BNIP3 mediated apoptosis was not inhibited by any anti-apoptotic genes. This explains the susceptibility of these MCTSs to PDT compared to monolayer cultures and $500 \mu \mathrm{m}$ MCTSs where upregulation of pro-apoptotic genes was counteracted by anti-apoptotic genes. Photoactivated $\mathrm{ZnPcS}_{\text {mix }}$ seems to induce both the intrinsic and extrinsic apoptotic pathway in monolayer cells since there is the involvement of TNF signalling and BCL2 family members. In the MCTSs $(250$ and $500 \mu \mathrm{m})$ the pathway that was followed is inconclusive. However, it was shown that BNIP3-which is located in the cytosol or loosely attached to the mitochondrial outer membrane-played a critical role in the induction of caspase independent apoptosis. The downregulation of the BNIP3 gene has been associated with chemo-resistance in vivo and in our study the BNIP3 gene was upregulated in a tumour model that mimics an in vivo situation. This shows that photoactivated $\mathrm{ZnPcS}_{\text {mix }}$ may be effective in the treatment of cancer in vivo. Further studies to elucidate the failure of anti-apoptotic genes in MCTSs with a diameter size of $250 \mu \mathrm{m}$ are required. The understanding of the condition that resulted in the downregulation of anti-apoptotic genes in MCTSs $(250 \mu \mathrm{m})$ may play a critical role in designing efficient PDT protocols.

Acknowledgments: We thank Tebello Nyokong (Department of Chemistry, Rhodes University, South Africa) for the synthesis and provision of the photosensitizer and the National Laser Centre for use of their lasers. This work is based on the research supported by the South African Research Chairs Initiative of the Department of Science and Technology and National Research Foundation of South Africa (Grant No. 98337). 
Author Contributions: Sello L. Manoto, Nicolette Houreld, and Heidi Abrahamse conceived and designed the experiments. Sello L. Manoto performed the experiments. Sello L. Manoto and Natasha Hodgkinson analyzed the data. Sello L. Manoto and Natasha Hodgkinson wrote the paper.

Conflicts of Interest: The material in this paper submitted to Molecules has neither been published, nor is being considered elsewhere for publication.

\section{References}

1. Crous, A.; Abrahamse, H. High Fluence Low Intensity Laser Irradiation Bioinhibits Viability and Proliferation of Lung Cancer Stem Cells. J. Stem Cell Res. Ther. 2016. [CrossRef]

2. Zago, G.; Muller, M.; van den Heuvel, M.; Baas, P. New targeted treatments for non-small-cell lung cancer-Role of nivolumab. Biologics 2016, 10, 103-107. [CrossRef] [PubMed]

3. Ridge, C.A.; McErlean, A.M.; Ginsberg, M.S. Epidemiology of lung cancer. Semin. Interv. Radiol. 2013, 30, 93-98. [CrossRef] [PubMed]

4. Allemani, C.; Weir, H.K.; Carreira, H.; Harewood, R.; Spika, D.; Wang, X.S.; Bannon, F.; Ahn, J.V.; Johnson, C.J.; Bonaventure, A.; et al. Global surveillance of cancer survival 1995-2009: Analysis of individual data for 25, 676, 887 patients from 279 population-based registries in 67 countries (CONCORD-2). Lancet 2014, 385, 977-1010. [CrossRef]

5. Wu, K.; House, L.; Liu, W.; Cho, W. Personalized targeted therapy for lung cancer. Int. J. Mol. Sci. 2012, 13, 11471-11496. [CrossRef] [PubMed]

6. Hirsch, F.R.; Suda, K.; Wiens, J.; Bunn, P.A. New and emerging targeted treatments in advanced non-small-cell lung cancer. Lancet 2016, 388, 1012-1024. [CrossRef]

7. Wan, M.T.; Lin, J.Y. Current evidence and applications of photodynamic therapy in dermatology. Clin. Cosmet. Investig. Dermatol. 2014, 7, 145-163. [CrossRef] [PubMed]

8. De Paula, L.B.; Primo, F.L.; Pinto, M.R.; Morais, P.C.; Tedesco, A.C. Combination of hyperthermia and photodynamic therapy on mesenchymal stem cell line treated with chloroaluminum phthalocyanine magnetic-nanoemulsion. J. Magn. Magn. Mater. 2015, 380, 372-376. [CrossRef]

9. Calixto, G.M.F.; Bernegossi, J.; de Freitas, L.M.; Fontana, C.R.; Chorilli, M. Nanotechnology-based drug delivery systems for photodynamic therapy of cancer: A review. Molecules 2016, 21, 342. [CrossRef] [PubMed]

10. Abrahamse, H.; Hamblin, M.R. New photosensitizers for photodynamic therapy. Biochem. J. 2016, 473, 347-364. [CrossRef] [PubMed]

11. Agostinis, P.; Berg, K.; Cengel, K.A.; Foster, T.H.; Girotti, A.W.; Gollnick, S.O.; Hahn, S.M.; Hamblin, M.R.; Juzeniene, A.; Kessel, D.; et al. Photodynamic therapy of cancer: An update. CA Cancer J. Clin. 2011, 61, 250-281. [CrossRef] [PubMed]

12. Obata, T.; Mori, S.; Suzuki, Y.; Kashiwagi, T.; Tokunaga, E.; Shibata, N.; Tanaka, M. Photodynamic Therapy Using Novel Zinc Phthalocyanine Derivatives and a Diode Laser for Superficial Tumors in Experimental Animals. J. Cancer Ther. 2014, 6, 53. [CrossRef]

13. Raghavan, S.; Ward, M.R.; Rowley, K.R.; Wold, R.M.; Takayama, S.; Buckanovich, R.J.; Mehta, G. Formation of stable small cell number three dimensional ovarian cancer spheroids using hanging drop arrays for preclinical drug sensitivity assays. Gynecol. Oncol. 2015, 138, 181-189. [CrossRef] [PubMed]

14. Edmondson, R.; Broglie, J.J.; Adcock, A.F.; Yang, L. Three-dimensional cell culture systems and their applications in drug discovery and cell-based biosensors. Assay Drug Dev. Technol. 2014, 12, 207-218. [CrossRef] [PubMed]

15. Gong, X.; Lin, C.; Cheng, J.; Su, J.; Zhao, H.; Liu, T.; Wen, X.; Zhao, P. Generation of multicellular tumor spheroids with microwell-based agarose scaffolds for drug testing. PLoS ONE 2015, 10, e0130348. [CrossRef] [PubMed]

16. Manoto, S.L.; Houreld, N.N.; Abrahamse, H. Resistance of lung cancer cells grown as multicellular tumour spheroids to zinc sulfophthalocyanine photosensitization. Int. J. Mol. Sci. 2015, 16, 10185-10200. [CrossRef] [PubMed]

17. Moscato, S.; Ronca, F.; Campani, D.; Danti, S. Poly (vinyl alcohol)/gelatin Hydrogels Cultured with HepG2 Cells as a 3D Model of Hepatocellular Carcinoma: A Morphological Study. J. Funct. Biomater. 2015, 6, 16-32. [CrossRef] [PubMed] 
18. Horiuchi, S.I.; Ishida, S.; Hongo, T.; Ishikawa, Y.; Miyajima, A.; Sawada, J.I.; Ohno, Y.; Nakazawa, K.; Ozawa, S. Global gene expression changes including drug metabolism and disposition induced by three-dimensional culture of HepG2 cells-Involvement of microtubules. Biochem. Biophys. Res. Commun. 2009, 378, 558-562. [CrossRef] [PubMed]

19. Wang, J.; Zhang, L.; Chen, M.; Gao, S.; Zhu, L. Activatable Ferritin Nanocomplex for Real-Time Monitoring of Caspase-3 Activation during Photodynamic Therapy. ACS Appl. Mater. Interfaces 2015, 7, 23248-23256. [CrossRef] [PubMed]

20. Silva, J.C.; Ferreira-Strixino, J.; Fontana, L.C.; Paula, L.M.; Raniero, L.; Martin, A.A.; Canevari, R.A. Apoptosis associated genes related to photodynamic therapy in breast carcinomas. Lasers Med. Sci. 2014, 29, 1429-1436. [CrossRef] [PubMed]

21. Manoto, S.L.; Houreld, N.N.; Abrahamse, H. Phototoxic effect of photodynamic therapy on lung cancer cells grown as a monolayer and three dimensional multicellular spheroids. Lasers Surg. Med. 2013, 45, 186-194. [CrossRef] [PubMed]

22. Kimlin, L.C.; Casagrande, G.; Virador, V.M. In vitro three-dimension: How 3D culture microenvironments alter cellular cues. J. Cell Sci. 2013, 52, 167-182.

23. LaRocca, T.J. Programmed cell death dynamics during hyperglycemia and ischemic brain injuries. J. Neurol. Neurorehabil. Res. 2016, 1, 7-12.

24. Vittar, N.B.R.; Awruch, J.; Azizuddin, K.; Rivarola, V. Caspase-independent apoptosis, in human MCF-7c3 breast cancer cells, following photodynamic therapy, with a novel water-soluble phthalocyanine. Int. J. Biochem. Cell Biol. 2010, 42, 1123-1131. [CrossRef] [PubMed]

25. Chen, Y.; Yang, L.N.; Cheng, L.; Tu, S.; Guo, S.J.; Le, H.Y.; Xiong, Q.; Mo, R.; Li, C.Y.; Jeong, J.S.; et al. Bcl2-associated athanogene 3 interactome analysis reveals a new role in modulating proteasome activity. Mol. Cell. Proteom. 2013, 12, 2804-2819. [CrossRef] [PubMed]

26. Youle, R.J.; Strasser, A. The BCL-2 protein family: Opposing activities that mediate cell death. Nat. Rev. Mol. Cell Biol. 2008, 9, 47-59. [CrossRef] [PubMed]

27. Tamura, R.; de Vasconcellos, J.F.; Sarkar, D.; Libermann, T.A.; Fisher, P.B.; Zerbini, L.F. GADD45 proteins: Central players in tumorigenesis. Curr. Mol. Med. 2012, 12, 634-651. [CrossRef] [PubMed]

28. Yin, F.; Bruemmer, D.; Blaschke, F.; Hsueh, W.A.; Law R, E.; van Herle, A.J. Signaling pathways involved in induction of GADD45 gene expression and apoptosis by troglitazone in human MCF-7 breast carcinoma cells. Oncogene 2004, 23, 4614-4623. [CrossRef] [PubMed]

29. Chang, I.; Majid, S.; Saini, S.; Zaman, M.S.; Yamamura, S.; Chiyomaru, T.; Shahryari, V.; Fukuhara, S.; Deng, G.; Dahiya, R.; et al. Hrk mediates 2-methoxyestradiol-induced mitochondrial apoptotic signaling in prostate cancer cells. Mol. Cancer Ther. 2013, 12, 1049-1059. [CrossRef] [PubMed]

30. Childs, B.G.; Baker, D.J.; Kirkland, J.L.; Campisi, J.; van Deurse, J.M. Senescence and apoptosis: Dueling or complementary cell fates? EMBO Rep. 2014, 15, 1139-1153. [CrossRef] [PubMed]

31. Ye, X.; Zhang, C.; Chen, Y.; Zhou, T. Upregulation of acetylcholinesterase mediated by p53 contributes to cisplatin-induced apoptosis in human breast cancer cell. J. Cancer 2015, 6, 48. [CrossRef] [PubMed]

32. Kumari, R.; Sen, N.; Das, S. Tumour suppressor p53: Understanding the molecular mechanisms inherent to cancer. Curr. Sci. 2014, 107, 786.

33. Karmakar, S.; Banik, N.L.; Patel, S.J.; Ray, S.K. 5-Aminolevulinic acid based photodynamic therapy suppressed survival factors and activated proteases for apoptosis in human glioblastoma U87MG cells. Neurosci. Lett. 2007, 415, 242-247. [CrossRef] [PubMed]

34. Zhang, X.; Bian, X.; Kong, J. The proapoptotic protein BNIP3 interacts with VDAC to induce mitochondrial release of endonuclease G. PLoS ONE 2014, 9, e113642. [CrossRef] [PubMed]

35. Zanoni, M.; Piccinini, F.; Arienti, C.; Zamagni, A.; Santi, S.; Polico, R.; Bevilacqua, A.; Tesei, A. 3D tumor spheroid models for in vitro therapeutic screening: A systematic approach to enhance the biological relevance of data obtained. Sci. Rep. 2016, 6. [CrossRef] [PubMed]

36. Guo, K.; Searfoss, G.; Krolikowski, D.; Pagnoni, M.; Franks, C.; Clark, K.; Yu, K.T.; Jaye, M.; Ivashchenko, Y. Hypoxia induces the expression of the pro-apoptotic gene BNIP3. Cell Death Differ. 2001, 8, 367-376. [CrossRef] [PubMed]

37. Portt, L.; Norman, G.; Clapp, C.; Greenwood, M.; Greenwood, M.T. Anti-apoptosis and cell survival: A review. Biochim. Biophys. Acta 2011, 1813, 238-259. [CrossRef] [PubMed] 
38. Byun, J.; Lee, G.; Choi, H.; Myung, K.; Choi, Y. The expressions of TGF- $\beta 1$ and IL10 in cultured fibroblasts after ALA-IPL photodynamic therapy. Ann. Dermatol. 2011, 23, 19-23. [CrossRef] [PubMed]

39. Vogler, M. BCL2A1: The underdog in the BCL2 family. Cell Death Differ. 2012, 19, 67-74. [CrossRef] [PubMed]

40. Kolluri, S.K.; Zhu, X.; Zhou, X.; Lin, B.; Chen, Y.; Sun, K.; Tian, X.; Town, J.; Cao, X.; Lin, F.; et al. A short Nur77-derived peptide converts Bcl-2 from a protector to a killer. Cancer Cell 2008, 14, 285-298. [CrossRef] [PubMed]

41. Quinsay, M.N.; Thomas, R.L.; Lee, Y.; Gustafsson, A.B. Bnip3 mediated mitochondrial autophagy is independent of the mitochondrial permeability transition pore. Autophagy 2010, 6, 855-862. [CrossRef] [PubMed]

42. John, T.; Müller, R.D.; Oberholzer, A.; Zreiqat, H.; Kohl, B.; Ertel, W.; Hostmann, A.; Tschoeke, S.K.; Schulze-Tanzil, G. Interleukin-10 modulates pro-apoptotic effects of TNF- $\alpha$ in human articular chondrocytes in vitro. Cytokine 2007, 40, 226-234. [CrossRef] [PubMed]

43. Gollnick, S.O.; Liu, X.; Owczarczak, B.; Musser, D.A.; Henderson, B.W. Altered expression of interleukin 6 and interleukin 10 as a result of photodynamic therapy in vivo. Cancer Res. 1997, 57, 3904-3909. [PubMed]

44. Zeng, L.; Li, T.; Xu, D.C.; Liu, J.; Mao, G.; Cui, M.Z.; Fu, X.; Xu, X. Death receptor 6 induces apoptosis not through type I or type II pathways, but via a unique mitochondria-dependent pathway by interacting with Bax protein. J. Biol. Chem. 2012, 287, 29125-29133. [CrossRef] [PubMed]

45. Benschop, R.; Wei, T.; Na, S. Tumor necrosis factor receptor superfamily member 21: TNFR-related death receptor-6, DR6. In Therapeutic Targets of the TNF Superfamily; Grewal, I.S., Ed.; Springer: New York, NY, USA, 2009; pp. 186-194.

Sample Availability: The human lung cancer cell line (A549, ATCC ${ }^{\circledR}$ CCL-185) is available from the ATCC. The $\mathrm{ZnPcS}_{\text {mix }}$ was produced by the organic chemistry department. Both these are readily available.

(c) 2017 by the authors. Licensee MDPI, Basel, Switzerland. This article is an open access article distributed under the terms and conditions of the Creative Commons Attribution (CC BY) license (http://creativecommons.org/licenses/by/4.0/). 